\title{
Effects of anthropogenic fragmentation on the biodiversity of plants in northern meadow steppes
}

\author{
Sergey Bakka $^{1^{*}}$, Nadezhda Kiseleva ${ }^{2}$, and Anna Shestakova ${ }^{3}$ \\ ${ }^{1}$ State Nature Reserve "Nurgush", 610000 Kirov, Russia \\ ${ }^{2}$ Minin Nizhny Novgorod State Pedagogical University, 603950 Nizhny Novgorod, Russia \\ ${ }^{3}$ Lobachevsky State University of Nizhny Novgorod, 603950 Nizhny Novgorod, Russia
}

\begin{abstract}
The paper is aimed to assess the effect of anthropogenic fragmentation on the biodiversity of plants in northern meadow steppes located in the southeast of the Nizhny Novgorod region. The plants were chosen as a model group. A quantitative analysis of the dependence of the number of species on the area of habitats was carried out according to the data collected at 158 sites of meadow steppes and steppe meadows with a total area of 10752 ha. For each of the meadow steppe and steppe meadows surveyed, the total area, proportion, and area covered with meadow steppe communities proper were determined, and a floristic list was compiled, in which species characteristic of meadow steppes were identified. Totally flora lists 361 species of plants, including 110 steppe species. It is shown that ecological interactions between separate fragments of meadow steppe in the south-east of Nizhny Novgorod region are broken; the remained fragments of meadow steppe are isolated. To conserve biological diversity in the forest-steppe zone, the special measures aimed at the ecological restoration of interactions between meadow steppe fragments is necessary.
\end{abstract}

Fragmentation of natural habitats of wildlife organisms by elements of human infrastructure is an important factor affecting species diversity and number. Destruction of habitats on a part of their former range turns their remnants into isolated islands from each other, on which island effects (reduction of biodiversity due to reduction of the area of habitats) are manifested [1,2].

In order to conserve biodiversity, it is important to know and identify areas where ecological interactions between remained fragments of natural habitats are destroyed, there is a loss of species of living organisms as a result of island effects, it is necessary to take measures of ecological restoration.

Previously, we studied the effect of anthropogenic fragmentation on species richness and diversity in the southern taiga in the Nizhny Novgorod region. Here old-growth forest patches are highly fragmented and have a small area. However, the remained fragments of high-growth dark-coniferous taiga are mainly located inside large forest areas transformed and rejuvenated by cuttings and fires of different years. It has been shown that under these

\footnotetext{
* Corresponding author: sopr_nn@mail.ru
} 
conditions, ecological interactions (exchange of species and individuals) between highgrowth taiga fragments are remained $[3,4]$.

Meadow steppes and watershed oak forests, zonal ecosystems of the forest-steppe zone, are the most strongly transformed and fragmented. The remained fragments of meadow steppes are small islands surrounded by cultivated lands [5, 6]. Under these conditions, we can expect a pronounced manifestation of island effects. The study of this phenomenon is extremely relevant, the results can serve as a basis for the feasibility of ecological restoration of meadow steppes. This work will be a good contribution to solving the problems of the decade of ecological restoration (United Nations Decade on Ecosystem Restoration 2021-2030).

The main method for identifying "island effects" in natural ecosystems is to analyze the relationship between the number of species and the area of habitats. It is expressed using the formula: $\mathrm{S}=\mathrm{CA}^{\mathrm{z}}$, where $\mathrm{S}$ is the number of species, $\mathrm{A}$ is the area, and $\mathrm{z}$ and $\mathrm{C}$ are dimensionless parameters whose value should be chosen for each specific set of data on the number of species and areas. A logarithmic transformation of this function results in a linear relationship. This allows the value of $\mathrm{z}$ to be calculated by analyzing the linear equation $\log \mathrm{S}=\mathrm{z} \log \mathrm{A}+$ constant. In this equation, $\mathrm{z}$ characterizes the slope of the straight line graph of a given function. The $\mathrm{z}$ values vary depending on whether the object being characterized is really an isolate or just a sample. The range of $\mathrm{z}$ values from 0.12 to 0.17 is typical for samples, and from 0.18 to 0.35 for isolates [1].

To assess the preservation of ecological interactions and identify the presence of island effects, we surveyed 158 areas of meadow steppes and steppe meadows in 2013-2014 with a total area of 10752 ha in the southeastern Nizhny Novgorod region. For this purpose, we laid $9,235 \mathrm{~km}$ of vehicle and $418 \mathrm{~km}$ of pedestrian routes.

The plants were chosen as the model group. The total area, proportion, and area occupied by meadow steppe communities proper were determined for each of the surveyed sites (using satellite images, GIS-methods, and data of surveys). Also a list of species was compiled for each site, in which species characteristic of meadow steppes were highlighted. The total floristic list was 361 plant species, including 110 steppe species. The area of surveyed sites varied from 4.3 ha to 294.5 ha, the area covered with steppe associations there was from 0.0 ha to 135.3 ha (Table 1 ).

Table 1. Characteristics of the studied meadow steppe and steppe meadows

\begin{tabular}{|c|c|c|c|c|}
\hline Index & $\begin{array}{c}\text { Total area of } \\
\text { the site, ha }\end{array}$ & $\begin{array}{c}\text { Area of } \\
\text { steppe } \\
\text { association } \\
\text { s, ha }\end{array}$ & $\begin{array}{c}\text { Total number } \\
\text { of plant } \\
\text { species }\end{array}$ & $\begin{array}{c}\text { Number of } \\
\text { steppe plant } \\
\text { species }\end{array}$ \\
\hline Minimum & 4.30 & 0.00 & 13 & 0 \\
\hline Maximum & 294.48 & 135.31 & 178 & 76 \\
\hline Mean & 68.05 & 13.92 & 67 & 23 \\
\hline $\begin{array}{c}\text { Standard } \\
\text { deviation }\end{array}$ & 56.71 & 24.13 & 45 & 16 \\
\hline $\begin{array}{c}\text { Confidence } \\
\text { interval }\end{array}$ & $59.21-76.89$ & $\begin{array}{c}10.16- \\
17.69\end{array}$ & $60-74$ & $20-25$ \\
\hline Total & 10751.74 & 2199.99 & 361 & 110 \\
\hline
\end{tabular}


Based on the results of the surveys, we made graphs characterizing the quantitative relationship between the number of plant species and the area of habitats using Excel tools. We plotted the logarithm of the number of species (S) along the vertical axis (Y) and the logarithm of the area (A) along the horizontal axis (X), placing points corresponding to specific values of these values for the studied meadow steppe areas. Linear dependence was plotted using the method of least squares on the obtained points. Using Excel tools, the equation of the function was composed and the value of the coefficient $\mathrm{z}$ was determined (Fig. 1, 2).

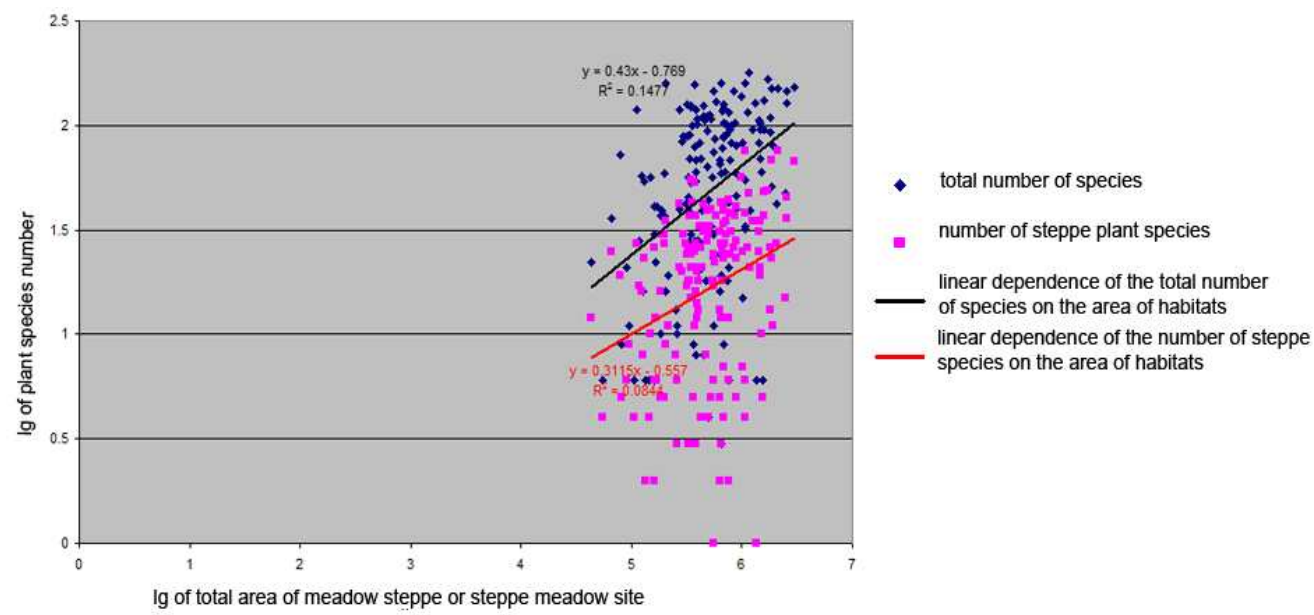

Fig. 1. Dependence of the plant species number on the total area of a meadow steppe or steppe meadow site in the Nizhny Novgorod region

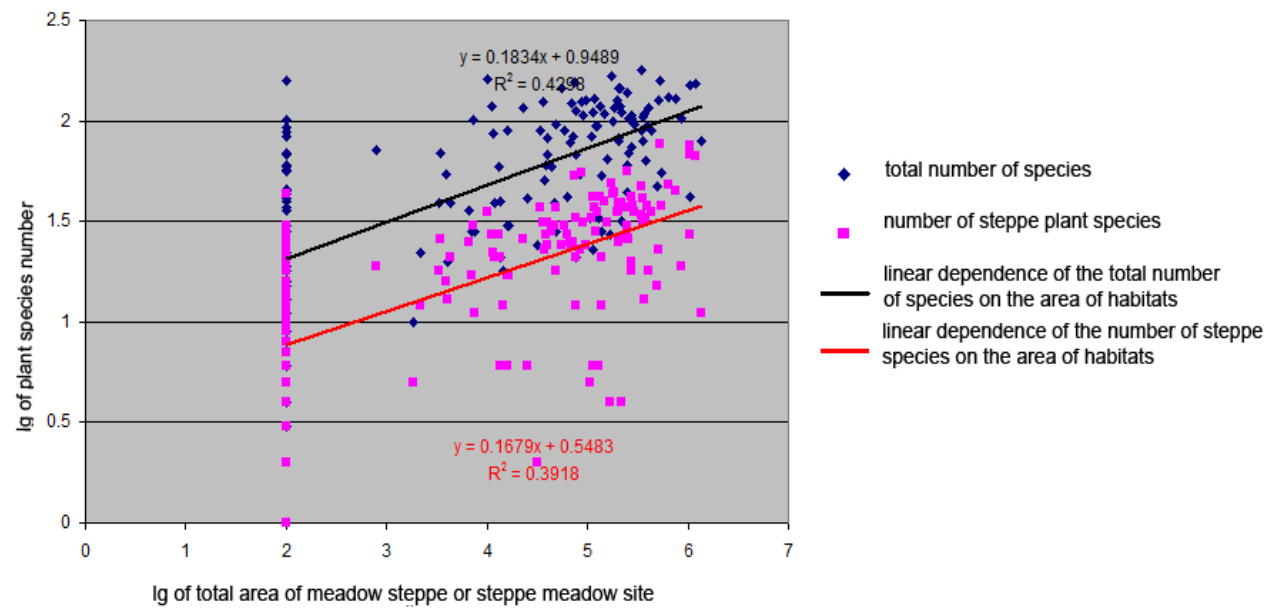

Fig. 2. Dependence of the number of plant species on the area of steppe associations in a meadow steppe or steppe meadow site in the Nizhny Novgorod region.

Fig. 1 shows that in the formula for the relationship between the number of species and the total area of habitats $\left(\mathrm{S}=\mathrm{CA}^{\mathrm{z}}\right)$ in the meadow steppe and steppe meadows of the Nizhny Novgorod region, the index of degree $\mathrm{z}$ is 0.43 for the total number of plant species and 0.31 for steppe species. Such values of this index are characteristic of isolates rather than samples. Consequently, ecological relationships between separate fragments of meadow 
steppe in the southeast of Nizhny Novgorod region are disrupted, and there is a loss of species as a result of island effects.

Calculation of the quantitative dependence of the plant species number on the area of steppe associations in meadow steppes or steppe meadow sites (Fig. 2) did not show such a clear expression of island effects. The z-score was $0.17-0.18$, which corresponds to the upper limit of this value characteristic of the samples. This can be explained by the fact that there is no functional relationship between the total area of meadow steppe and steppe meadow sites and the area of steppe associations on them, and the correlation coefficient is only 0.65 . The area of steppe associations may be larger on medium-sized steppe sites than on large sites with higher floristic richness.

Thus, the natural framework of ecological stability in the forest-steppe zone in the southeast of the Nizhny Novgorod region is destroyed. Separate remaining fragments of meadow steppes are isolates, ecological relationships between which are broken. There is a manifestation of island effects. To conserve biodiversity in the forest-steppe zone it is necessary ecological restoration, aimed at recovery of ecological relations between meadow steppe fragments. Part of the arable lands should be transformed into pastures and hayfields.

One of the ways to develop an ecological framework is to create an archipelago of fragments of natural ecosystems. The islets must be located close enough to allow the transfer of matter and energy and the exchange of individuals of most species of living organisms. Currently, in the Nizhny Novgorod forest-steppe the latter condition is not observed. It is essential to restore additional areas of meadow steppe, as well as ecological corridors between the remaining fragments of.

The presented conclusions are drawn on one model group of wildlife - plants. It is reasonable to confirm them on the data of other taxa (e.g., invertebrate animals).

\section{References}

1. M. E. Soule, Conservation biology: the science of scarcity and diversity. (1986)

2. T. Žuna Pfeiffer, D. Špoljarić Maronić, S. Petrošanec, I. Štolfa Čamagajevac, F. Stević, Plant Biosystems, 152(5) (2018).

3. S. V. Bakka, N. Y. Kiseleva, Ecology, Environment and Conservation, 23(4) (2017)

4. S. V. Bakka, N. Yu. Kiseleva, M. A. Glybina, Evaluation of the influence of anthropogenic fragmentation of intact ecosystems of the southern taiga of the Nizhny Novgorod region on species diversity of model groups of living organisms. RJPBCS, 9 (5) (2018).

5. A. T. Kharitonychev, The nature of the Nizhny Novgorod Volga region: history, use, protection (Gorky, Volgo-Vyatka book publishing house, 1978)

6. S. V. Bakka, N. Y. Kiseleva, A. A. Shestakova et al., Current status, problems and prospects of conservation of meadow steppes in the Nizhny Novgorod region. IOP Conf. Ser., Earth Environ. Sci. 543(1) (2020) 